\title{
El discurso político en momentos de campaña electoral. Una aproximación desde el Análisis Crítico del Discurso
}

\author{
Marcelo Criollo \\ FLACSO, QUITO, ECUADOR \\ marcelocriollocb@gmail.com
}

\begin{abstract}
Resumen: El objetivo de este artículo es presentar un aporte teórico y metodológico de Análisis Crítico del Discurso aplicado al discurso político. El trabajo propone una revisión conceptual de las diferentes orientaciones, planos y propuestas de esta técnica de análisis cualitativo desde el enfoque de género. El corpus se conformó con la selección de Planes de Gobierno de los partidos políticos participantes en la campaña electoral 2017 en Ecuador en contexto con spots de campaña electoral los cuales son considerados como unidades de contexto útiles para la interpretación y análisis de los textos. Esta investigación toma como pilar la teoría foucaultiana del poder y el discurso, la propuesta es entender al discurso como un instrumento de poder. Como conclusión, los hallazgos revelan los límites de la democracia de tipo liberal y el uso de una serie de recursos discursivos que legitiman los prejuicios y los estereotipos. A partir de la identificación de una serie de cualificaciones y otros recursos como la institucionalidad, la religión o las tradiciones, se observa la manera en la que estas cuestiones son vistas como principios que determinan la veracidad y las exigencias para entrar en el orden mismo del discurso.
\end{abstract}

Palabras clave: poder; discurso; género; elecciones.

Abstract: The objective of this article is to present a theoretical and methodological contribution of Critical Analysis applied to political discourse. The research proposes a conceptual review of the different orientations, plans and proposals of this qualitative analysis technique from a gender perspective. The corpus was set up by the selection of Government Plans of the political parties participating in the 2017 election campaign in Ecuador in context with campaign spots which are consider as suitable context units for the interpretation and analysis of the texts. This research takes as its underlying fundament the Foucaultian theory of power and discourse, the proposal is to understand speech as an instrument of power. In conclusion, the findings reveal the limits of liberal democracy and the use of a series of discursive resources that legitimize prejudices and stereotypes. A range of qualifications and other resources such as institutionalism, religion or traditions were identified and subsequently analyzed in order to know why they are considered as principles that determine truthfulness and the requirements to enter the order of a discourse.

Keywords: power; discourse; gender; elections. 


\section{Introducción}

sta investigación aporta con una articulación teórica y metodológica del estudio de las relaciones de género en el nivel enunciativo de los discursos políticos, vinculados a la conceptualización de poder-saber-verdad. La problemática a desarrollar apunta a la tensión teórica alrededor del discurso y su relación con la desigualdad social, las luchas por el poder y aspectos profundamente discriminatorios, "retoricas de exclusión" que circulan en el discurso, entendido este como un instrumento de poder al cual tienen acceso determinadas elites políticas.

En este contexto el ACD, (Análisis Crítico del Discurso), como una disciplina de estudio abre el debate sobre las relaciones sociales que se producen en el texto y en el habla, relaciones que a menudo implican dimensiones desiguales de poder, de género, étnicas, etc. El ACD se interesa por el estudio del abuso del poder social dentro de un contexto social y político determinado, se trata según la teórica feminista Nancy Fraser (2003) de una orientación a favor del reconocimiento de la diferencia, en donde el discurso juega un rol central en lo concerniente a la reproducción de las relaciones de poder. Siguiendo los aportes de Van Dijk (2009:76) las prácticas discursivas producen y reproducen relaciones de poder desiguales, las mismas que se dan entre diferentes clases sociales, entre mujeres y hombres, blancos y negros, nacionales y extranjeros, heterosexuales y homosexuales, etc., el discurso puede presentarse como racista o sexista, puede legitimar o proyectar prejuicios, estereotipos o representaciones negativas; relaciones de poder que no suelen resultar evidentes, "el ACD se propone lograr que estos aspectos opacos del discurso se vuelvan más transparentes" (Fairclough y Wodak, 2008:368).

Ahora bien, dada la variedad de tipos de discursos existentes el presente artículo muestra un análisis al discurso político, enunciados caracterizados por ser de interés público, mensajes en donde se apela al reclamo público sobresaliente, que con frecuencia deslegitima ciertos intereses para valorizar otros (Fraser, 1997:126), discursos que develan ciertos aspectos como los modos de exclusión y dominación de lo masculino sobre lo femenino, la discriminación entre grupos o en sentido teórico las dimensiones del poder como atributo de género o de manera más general las relaciones de poder entre nosotros y ellos (Van Dijk, 2009:76). Como ejemplo práctico de análisis textual, presentamos el análisis al discurso político oficial extendido concretamente a los Planes de Gobierno cuyo contenido se destaca por contener un mensaje de estilo idealizado, del deber ser y del bien común y en los que los "asuntos privados" son muchas veces indeseables (Fraser, 1997:108). 


\section{Marco teórico}

¿Qué es el Análisis Crítico del Discurso? Desde el punto de vista epistemológico, analizar los discursos se corresponde con un enfoque particular del papel del lenguaje, principalmente anclado en la teoría crítica y ocupándose no solo de los elementos lingüísticos sino de la función del lenguaje en relación con la representación del mundo y la realidad, consolidándose como una herramienta útil para leer textos que requieren ser releídos para su correcta interpretación. En palabras de Foucault,

Se trata de hacer aparecer las prácticas discursivas en su complejidad y en su espesor; mostrar que hablar es hacer algo, algo distinto a expresar lo que se piensa, traducir lo que se sabe, distinto a poner en juego las estructuras de una lengua; mostrar que agregar un enunciado a una serie preexistente de enunciados, es hacer un gesto complicado y costoso, que implica unas condiciones (Foucault, 1988:351).

En esta misma línea, y en sentido específico ¿a qué nos referimos con los términos poder discursivo? ¿Cuáles son sus implicaciones y alcances? Para responder a estas interrogantes proponemos en primer lugar la definición foucaultiana de poder;

Por poder hay que comprender, primero, la multiplicidad de las relaciones de fuerza inmanentes y propias del dominio en que se ejercen, y que son constitutivas de su organización; el juego que, por medio de luchas y enfrentamientos incesantes, las transforma, las refuerza, las invierte; los apoyos que dichas relaciones de fuerza encuentran las unas en las otras, de modo que formen cadena o sistema (Foucault, 1989:113).

Otros autores como Teun A. Van Dijk, definen al poder en términos de control;

Definiré esencialmente el poder (social) en términos de control; es decir el que un grupo o institución ejerce sobre otras personas. Dicho control puede ser coercitivo, esto es control físico directo del cuerpo, como en el caso de la milicia, el poder policial o el poder de hombres sobres mujeres en casos de violencia, sexista. Sin embargo, el poder discursivo es más bien mental (Van Dijk, 2004:9).

Siguiendo líneas foucaultianas, señalamos que el poder se articula a formas del saber, Foucault (1989) diría que el saber y el poder se entrelazan. La discursividad es un ámbito fundamental para estudiar las relaciones de poder-saber pues en las interacciones comunicativas que tienen carácter productivo no espontáneo es dónde se producen los roles de género, las necesidades, las identidades, las jerarquías; todo esto en las formas de saber, en determinados discursos de verdad que transmiten efectos de poder. 
Respecto al discurso, lo entendemos como una "práctica social". Foucault (1988) lo define como un conjunto de secuencias de signos, en tanto que éstos son enunciados. Entendemos al discurso, o conjunto de los enunciados, como un dispositivo de la construcción de la realidad social y como un instrumento de poder. El discurso, de acuerdo con Foucault, como un objeto de deseo, "aquel poder del que quiere uno adueñarse" (Foucault, 2002:6). Con estas consideraciones teóricas la dominación discursiva, es entendida como el abuso de poder que se da por medio del discurso, con el cual se construyen modelos o representaciones mentales.

Por otra parte, siguiendo la propuesta del orden del discurso de Michel Foucault (2002) se presupone la existencia de una serie de condiciones de producción de discursos que no son reducibles a la significación, por el contrario, proyectan un determinado orden social, así como procedimientos de exclusión y prohibición como aquellos que rigen sobre temas relativos a la sexualidad y la política. De acuerdo con Foucault,

En toda sociedad la producción del discurso está a la vez controlada, seleccionada y redistribuida por un cierto número de procedimientos que tienen por función conjurar los poderes y peligros (Foucault, 2002:14).

Desde ese punto de vista, es preciso plantear que el discurso lejos de ser un elemento transparente o neutro, es más bien el lugar en donde se ejerce el poder, se delimita un tipo de ordenamiento del discurso a través de procedimientos que determinan exclusiones; se construye la dominación, la violencia y la resistencia. Como parte de ese ordenamiento citamos; la cualificación del sujeto que habla, el principio de exterioridad, la interdiscursividad, la voluntad de verdad, los tabúes o lo no dicho y el más evidente: lo prohibido.

\subsection{El método y la técnica del Análisis Crítico del Discurso.}

La técnica cualitativa del ACD podría describirse como una técnica compleja en el sentido de no tener un método único, por el contrario, existen varios métodos y corrientes epistemológicas que hacen de esta técnica un resultado del diálogo entre varias propuestas ajustadas a los fines de cada investigación.

Así, por ejemplo, autores como Norman Fairclough y Michael Halliday proponen y desarrollan la idea de la teoría lingüística multifuncional, enfoque preocupado por la relación entre el lenguaje con otros elementos y aspectos de la vida social. Su enfoque está orientado al carácter social de los textos, el lenguaje como algo configurado por las funciones sociales "a las que ha terminado sirviendo" (Fairclough, 2003: 186). Por otra parte, Ruth Wodak y Van Dijk se introducen en el plano sociocognitivo 
o carácter social de los textos. Adicionalmente, Wodak ofrece el enfoque de análisis histórico y una orientación al género y el racismo.

Para Norman Fairclough (2008) el ACD explora sistemáticamente las relaciones entre prácticas discursivas, eventos y textos; estructuras, procesos y relaciones sociales. De manera similar, Halliday proporciona una visión general de su teoría funcional del lenguaje, una teoría que ve al lenguaje desde una perspectiva socio-semiótica (Halliday, 1982). Otra característica relevante del ACD de acuerdo con Fairclough (1995) es su reflexión acerca de la interdiscursividad, para el autor al discurso le preceden otros discursos. En sentido similar Angenot aclara que "todo texto aparece como una costura y un zurcido de collages heterogéneos de fragmentos erráticos del discurso social" (Angenot, 2010:22).

En cuanto al método histórico propuesto por Ruth Wodak, indicamos que este enfoque consiste en "integrar sistemáticamente toda la información disponible del contexto al análisis y la interpretación de las numerosas capas que constituyen un texto hablado o escrito" (Fairclough y Wodak, 2008:378). No es posible la producción de un discurso sin contexto o de sus condiciones externas, los discursos solo pueden ser entendidos y analizados por referencia a su contexto y todo el conocimiento disponible de fuentes históricas, fuentes orales, periódicos, debates televisados (Wodak, 2003:104) o spots de campaña electoral y entrevistas en medios como parte de nuestra propuesta de análisis.

Entre algunas herramientas analítico-discursivas o categorías de análisis del trabajo de Wodak y útiles para este estudio mencionamos las siguientes:

- Referencia o modo de nombrar.

- Predicación o etiquetado de los actores sociales.

- Argumentación: Justificación de las atribuciones tomadas como positivas o negativas. Esto nos lleva a reconocer la fuente de los discursos; el principio de trastocamiento según Foucault (2002).

- Presentación positiva o negativa de uno mismo o los otros: Construcción discursiva del nosotros y el ellos como fundamento de los discursos de identidad y diferencia. El ejercicio del poder se hará evidente en el control desequilibrado del diálogo, de la atribución de turnos, de los actos del habla, la elección de los temas, el estilo.

- Sujeto hablante o enunciador: Según el enfoque enunciativo del ACD esta noción es necesaria para conocer la posición del sujeto del discurso. Esta noción nos conduce a los saberes, opiniones, creencias del sujeto (Charaudeau, 2005) y las prácticas que a manera de ritual "define la cualificación que deben poseer los individuos que hablan" (Foucault, 2002:39) y los ámbitos institucionales donde se establecen ciertas verdades. 
- Construcción de silencios y tabúes: Se trata de identificar las prohibiciones, delimitaciones o lo innombrable. Lo que no se puede hablar, el "tabú del objeto". (Foucault, 2002).

\section{Metodología}

Como objeto de estudio, para este análisis textual consideramos observar el texto de los Planes de Gobierno de la primera vuelta de las elecciones generales 2017 en Ecuador llevadas a cabo el 19 de febrero del mismo año. Justificamos la selección de la temporalidad de este estudio, pues las elecciones del año 2017, y en general los procesos políticos, se presentan como relevantes desde la perspectiva de la búsqueda de votos, un clima propicio para propuestas, reclamos, negociaciones y demandas enfrentadas por diferentes campos de poder, clases y grupos sociales (Crespo, Garrido, y Riorda, 2008) y en donde la temática del género no es del todo ignorada. Estas elecciones también son vistas desde del fin de una década caracterizada por una mayor estabilidad política, por lo que aportamos con un estudio que permita rastrear y analizar uno de los distintos discursos que se fueron emanando anterior a una ruptura política tras diez años de gobierno.

Ahora bien, en lo que respecta al armado de nuestro corpus, se eligieron cuatro Planes (Alianza País, Creo-Suma, Partido Social Cristiano, Fuerza Ecuador), seleccionados de acuerdo a los siguientes criterios de representatividad: mayor porcentaje de voto por partido político, por género; se incorpora un partido que tiene una candidata presidenciable, partido histórico o tradicional y un partido nuevo pero que responde a una raíz histórica bien definida. En cuanto a las unidades de análisis que consideramos adecuadas para este estudio cualitativo las clasificamos de acuerdo a tópicos o ideas centrales que sirven de hilo conductor del discurso. En nuestro trabajo el tópico representa a un pequeño fragmento del discurso que determina qué se está diciendo en su totalidad (Pilleux, 1995: 127). Los tópicos que hemos seleccionado son aquellos que se relacionan con nuestros objetivos, estos son: familia, hombres $y$ mujeres, diversidad, minorías, género, LGBTI, sexualidad. El procedimiento básico consistió en clasificar las oraciones que de punto a punto se correspondan con cada tópico. Para el registro, hemos identificado los tópicos en cada Plan de Gobierno analizado otorgándoles etiquetas representadas con el nombre de los tópicos en cuestión con ayuda del programa de análisis cualitativo Atlas.ti. Adicionalmente, tomando como referencia el método histórico discursivo de Wodak (2003), nuestra construcción del contexto analítico fue complementada con spots de campaña y entrevistas en medios, "unidades de contexto" que se requieren o admiten para la interpretación (Krippendorf ,1990). 


\section{Resultados}

En primer lugar, al referirnos al Plan del partido Fuerza Ecuador (FE), nos situamos frente a un discurso político que tiene el sello de la institución de la religión cristiana como mecanismo de legitimación y fuente de veracidad discursiva. En ese sentido, el candidato Abdala Bucaram Pulley, quien se perfila como el hablante del discurso encarna también una modalidad discursiva vinculada a la religión cristiana.

El candidato presidencial se define a sí mismo como un hombre de fe, admite en su discurso formas específicas de manifestar e interpretar conceptos que se asocian al género. En función de nuestros tópicos de análisis, el corto Plan del candidato no hace ninguna mención explícita sobre el género, sin embargo, en el análisis se reconoció que el texto se concentra en el tópico familia:

Proteger al ciudadano frente a la delincuencia como su deber primordial, desarrollar una estrategia de política pública de tolerancia cero a las drogas en aras del fortalecimiento de la familia como núcleo principal de la estructura social. Devolviéndole la alegría, la esperanza y el bienestar, impulsando una política de valores que busque el bienestar y la paz social de todas las FAMILIAS ecuatorianas (Plan de Gobierno Fuerza Ecuador, 2016: 3).

Explícitamente el texto no define ni expone cómo se piensa y defiende a la familia en concreto, sin embargo en nuestras unidades de contexto observamos que el candidato se compromete con respetar el matrimonio y la familia según la visión cristiana, los derechos y los valores de los creyentes en Dios y que son constituidas por un hombre, una mujer y sus hijos (Unsion TV, 2013), sobre ese modelo recaerían las propuestas de políticas públicas que se expone, cuestiones que desconocen las identidades sociales y las interacciones discursivas que se realizan fuera de la familia nuclear.

El enunciador encuentra en el discurso religioso los límites de lo que se puede hacer y decir, satisface las exigencias de la utilización del discurso en el sentido de acompañarlo con un conjunto de signos religiosos, se constituye como una persona autorizada y calificada para hacerlo, Foucault (2002) diría, la cualificación que debe poseer el individuo que habla.

Lo no dicho: El Plan del partido Fuerza Ecuador no aborda de ninguna manera la temática del género, en concreto tampoco menciona a los colectivos LGBTI lo que implica un trato indiferente y silencioso sobre estos temas. De acuerdo con las teorías del género en el discurso, debemos prestar una atención más sistemática al silencio, pues las experiencias de subordinación se vuelven más transparentes cuando se observa no solo lo que se dice sino también lo que no se dice (West, Lazar y Kramarae, 2008), esto implica encontrar y descifrar los sentidos de los silencios en situaciones sociohistóricas, trasteando posibles significados de los silencios en los textos, 
ir a las condiciones externas de la aparición del discurso y la fijación de su sentido (Foucault, 2002).

Tomando en cuenta esos elementos notamos que la construcción del discurso sobre la diferencia sexual, en particular sobre la homosexualidad, ha operado como un "mecanismo de desprestigio político, ético y profesional debido a los arraigados discursos del patriarcado, del colonialismo y el conservadurismo religioso que generan interpretaciones homofóbicas en la red política y social del Ecuador" (Camacho, 2016:12).

Entre algunas de las declaraciones del sujeto hablante encontramos las siguientes expresiones sustantivas;

- Como puede hablar de valentía y de hombría aquel que no tienen la valentía, la hombría y la decencia de reconocer que es homosexual (RTU Noticias, 2012). - (Pregunta-Entrevistador) ¿Se reuniría con activistas por el matrimonio igualitario? (Respuesta-Bucaram) Sin ningún problema, pero aquí en mi casa (PLAN V, 2017).

- (Pregunta-Entrevistador) Usted ha dicho que la familia es el núcleo de la sociedad. ¿Y la familia LGBTI? (Respuesta-Bucaram) El Estado reconoce que las personas del mismo sexo pueden tener derechos similares a los de una pareja heterosexual y eso está en la Constitución (La Hora, 2017).

- (Sobre el matrimonio LGBTI) Mi recomendación para esas minorías es que constituyan una organización política y luchen por esas tesis, porque nosotros somos contrarios a eso y no las vamos a promover. Lo que vamos a hacer es un gran llamado a consulta nacional y que ahí estos grupos minoritarios tendrán el derecho de plantear sus tesis y ver si son sometidas a decisión del pueblo (...) El matrimonio es entre el hombre y la mujer y respetaremos lo que está en la Constitución (El Comercio, 2016).

Programa de Gobierno “Cambio Positivo": En lo concerniente al segundo plan analizado, presentamos el discurso de la única candidata mujer a la presidencia para el período 2017-2021. Veremos que en este análisis las formaciones discursivas se desarrollan en un contexto en el que prevalecen formas dominantes de masculinidad que vinculan a la mujer con la vida doméstica, ligadas al papel del cuidado de los hijos y en oposición a los hombres vinculados con actividades de la vida pública (Rosaldo, 1979).

Cynthia Viteri, figura como candidata del Partido Social Cristiano (PSC), agrupación política con bases ideológicas conservadoras e impregnada por el clericalismo y las posturas elitistas. Jaime Nebot, exalcalde de Guayaquil y figura importante dentro de este partido político, fue quien se encargó de anunciar la candidatura de Viteri. En rueda de prensa manifestó; "ahora que caminábamos por la calle alguien me dijo: 
"Abogado, Cynthia es el hombre". Y yo creo con sinceridad que el Ecuador tiene un candidato mejor que yo" (Jaime Nebot, 2016). Consideramos cuestionar estas declaraciones desde la valoración y el prestigio del sujeto varón al ocupar puestos de jerarquía, "metáforas de la subordinación" que asocian la masculinidad con ciertos valores y actividades sociales (Strathern, 1979:142).

Ya en el escenario político de la candidata se evidencia una cultura machista enraizada específicamente en la asignación de roles entre hombres y mujeres. Los tópicos que logramos identificar para proceder con el análisis fueron; familia, minorías, y hombre y mujer.

La candidata, quien goza de un amplio capital simbólico acumulado; exdiputada y exasambleísta, exvicepresidenta del congreso y candidata presidenciable por dos ocasiones posicionó una imagen maternal en su campaña. Una de sus declaraciones exponía: "tengan la certeza de que las madres jamás abandonamos. Este es mi país, este es mi hogar y ustedes son mi familia"”.

Respecto a las líneas del Plan analizado, se pudo observar el manejo de los tópicos hombre y mujer en el eje salarios, la propuesta es la de un salario equitativo entre ambos. No se hace mención a la población sexo diversa, la discriminación laboral o sus derechos. En el Plan brevemente se habla de las profesiones, las cuales denotan una construcción de grupos (hombres y mujeres) diferenciados por roles, el trabajo de las mujeres y el trabajo de los hombres (Lazar 2014). Se identificó la retórica de la maternidad como el eje de campaña y el rol de la madre protectora como parte del orden de las relaciones entre hombres y mujeres. Mencionamos algunas declaraciones del spot de campaña: Yo Voto Cynthia, Mujer Sociedad Actual

- "Yo creo que una persona, una mujer, tiene un poco más los pies sobre la tierra por el simple hecho de ser mujer". "El simple hecho de ser mamá le da una visión totalmente distinta a la naturaleza política que hemos tenido durante todo el tiempo que hemos vivido" (Yo Voto Cynthia, 2016a).

- "Estoy en cada madre que me entrego a su hijo (...) A la hora de votar este domingo piensa en tu familia, piensa en tus hijos, y recuerda, las madres jamás abandonamos, las madres unimos" (Yo Voto Cynthia, 2016b).

Por otra parte, el Plan incluye un párrafo dedicado a promover el respeto, los derechos y la no discriminación a las minorías de este discurso, sin enfocarse en grupos concretos; sean étnicos, culturales, sexuales.

1. Declaraciones emitidas por Viteri en el Diálogo Presidencial organizado por grupo El Comercio el 5 de febrero de 2017. 
Minorías. - Respeto, garantías, protección, defensa y difusión de sus derechos, pero fundamentalmente ningún discrimen. Los ciudadanos procederán según su ética personal en asuntos de conciencia, pero sin someterse irrestrictamente a la ley, que es de carácter general. Ninguna persona puede ser discriminada y las minorías no pueden ser víctimas por ello de maltrato o rechazo (Plan de Gobierno PSC, 2016: 11).

Sobre este párrafo, colectivos LGBTI consideran que proceder en asuntos de conciencia según la ética podría promover prácticas discriminatorias por ejemplo desde los servicios públicos que nieguen la atención a la población LGBTI por motivos éticos y religiosos (C. Paula, comunicación personal, 01 de junio de 2018).

También llama la atención que se construya un párrafo subtitulado con la palabra "minorías" sin ningún tipo de dato, sustento, o sobre quienes en concreto se está hablando, situación que puede poner en desventaja a grupos sobre los cuales caería una suerte de "tratamiento especial" o de poca importancia por representar a un número menor.

Finalmente, resulta interesante señalar que este Plan se define a sí mismo como "un instrumento orientado a definir y establecer los lineamientos generales en materia de acción política, económica y social, procurando satisfacer las necesidades más urgentes; pobreza, empleo y libertad" (Plan de Gobierno PSC, 2016: 2), no estamos frente a un texto apegado a la defensa de las diversidades sino a un texto que funciona dentro de los parámetros, exigencias y asuntos más universales "aquello que los participantes reconocen como un asunto de interés común” (Fraser, 1997:123).

Análisis del Plan de Gobierno CREO-SUMA: El político ecuatoriano Guillermo Lasso aparece como el actor implicado en el discurso que nos ocupa, forma parte del sistema político del país como actor de oposición del gobierno mandante durante el proceso electoral 2017. El candidato presenta una imagen basada en su experiencia exitosa en el área de las finanzas y la banca privada. En lo relacionado a temas sociales, el texto no muestra propuestas y avances significativos, no se incluyen criterios de género e igualdad. Sin embargo, en el análisis nos encontramos con dos tópicos que merecen ser focalizados, estos son: familia y diversidad, ambos conceptos forman parte de una estructura argumental presente en el Plan y desde donde se conciben diferentes temáticas como son la democracia, la economía, el trabajo, entre otros temas. "CREO es un movimiento político democrático, participativo e incluyente, que se inspira en los valores que nos unen como ecuatorianos; la libertad por un futuro mejor, la solidaridad con los menos favorecidos, y el amor por nuestra familia" (Plan de Gobierno CREO-SUMA, 2016:3).

A lo largo del discurso encontramos que se privilegia a la familia en torno a la economía y la calidad de vida. Siguiendo las líneas del Plan, la importancia por 
el bienestar de la familia es la visión ciudadana que reina en el país, las propuestas constantemente apuntan a un fin último; una economía dinámica que da lugar al bienestar de la familia en trabajo. Aquí se debe poner atención que se está hablando de una familia tradicional conformada por el padre, la madre y los hijos. En declaraciones, el candidato propuso que los hombres de los sectores campesinos puedan portar armas como medida de seguridad y cuidado de los suyos, lo que Bourdieu (2000) llamó manifestaciones de virilidad y hazaña que glorifica y enaltece. En ese caso la declaración del candidato tomó forma de dicho popular otorgando a la fuerza del hombre un valor de superioridad: "Vamos a permitir que puedan defender como varón a sus esposas y a sus hijos” (El Universo, 2016), afirmó el candidato. Ante los cuestionamientos sobre el uso de la expresión "como varón” el candidato dijo que eso es solo un accesorio. No se considera la importancia del lenguaje y otras formas de semiosis a través de las cuales se contribuye a la reproducción y el mantenimiento del orden social (Lazar, 2014).

A la par, en este discurso se establece una distinción entre roles de género: se habla de agricultores, comerciantes, trabajadores y amas de casa. El papel de la mujer aparece ligado a las tareas de la casa y de la familia, esto esta explícito en el Plan por ejemplo cuando la retórica del cuidado de los niños recae sobre la mujer/madre de forma "natural":

"Para atender las enfermedades que afectan a los niños, las madres acuden con ellos al centro de salud" (Plan de Gobierno CREO-SUMA, 2016:27). Se observa la construcción de grupos según el rol; el nosotros/ellos o "los jefes de hogar" y las "esposas", la clasificación de los roles sexuales.

Asimismo, el enunciador se sitúa en varias ocasiones en un discurso religioso ligado a lo familiar. El matrimonio para el candidato es la unión de dos personas de distinto sexo con un objetivo; la procreación (Gkillcity, 2017). En entrevista en medios el político menciona, "tengo mis principios y valores (...) somos católicos, apostólicos y romanos y creemos en los principios de la iglesia católica” (La Posta, 2015).

La diversidad aparece en varias ocasiones como una característica que se debe aprovechar y valorar en pro de un Ecuador unido, desarrollado y participativo. El Plan reza que el Ecuador es un país diverso tanto en sus regiones como en su población, líneas más abajo especifica: "diversas y diferentes realidades étnicas y culturales" (Plan de Gobierno CREO-SUMA, 2016:35), no menciona otras expresiones de diversidad como por ejemplo las diversidades sexuales. El texto también hace mención a los grupos vulnerables que son excluidos, pero en particular del mundo laboral, no da cuenta de otras formas de exclusión, discriminación o en el marco de la pluralidad y derechos. La declaración está sujeta al discurso económico, su aporte, dice el 
Plan "no solo es enriquecedor y diverso sino también imprescindible para construir el Ecuador del empleo y la solidaridad" (Plan de Gobierno CREO-SUMA, 2016:9).

La intertextualidad se manifiesta con la existencia de varias voces textuales, la tradición, la religión, el discurso biológico, la lógica de prioridades y finalmente la institucionalidad como forma de veracidad construida sobre los procedimientos de exclusión y prohibición (Foucault 2002), en este caso la influencia del principio constitucional de la unión de hecho como lo suficiente y necesario para los colectivos LGBTI.

A continuación, un ejemplo de lo que hemos dicho.
"Yo respeto, pero nadie en el Ecuador me dijo don Guillermo vengase el sábado para tomar una copita que Pedrito se va a casar con Pepito. Son temas de una minoría que yo respeto, no pueden invadir tanto como para decir esa minoría es la mayoría ahora en la sociedad. Ya existe en la Constitución la unión civil de dos personas de un mismo sexo, ¿Por qué llamar matrimonio? Yo creo que es suficiente la estructura legal del Ecuador para reconocer esa realidad social, no hace falta ningún cambio. Muchas veces son caprichos" (La Posta, 2015).

Plan de Gobierno ALIANZA PAÍS: En cuanto al Plan de Gobierno de Alianza País, rastreamos que los discursos de género entre otras temáticas mucho más amplias toman forma principalmente a partir de la articulación con otros discursos propios de un viraje populista. Este Plan que tiene impreso el sello del expresidente Rafael Correa hace especial énfasis en el conflicto y la división entre actores, hablamos de una dicotomización del espacio social en el que los actores se ven como participes de dos campos enfrentados (Laclau 2006).

En lo que respecta a los temas de género, la participación de la mujer y de las diversidades sexuales, el texto muestra importantes avances al visibilizar categorías omitidas en los análisis anteriores. Se encontraron algunas expresiones relacionadas con nuestros tópicos de análisis, estos son: diversidades (sexo-genéricas), LGBTI y (violencia) de género, estos conceptos aparecen en relación a temas de lucha por la igualdad, justicia social, derechos laborales y de salud, pero sobretodo como una de las luchas sociales abanderadas por programas sociales del movimiento Alianza País durante el mandato de Rafael Correa, también en referencia a la Constitución aprobada en el año 2008 que brindó cierto derechos a las poblaciones LGBTI y a los acontecimientos sucedidos a favor de las diversidades sexuales y étnicas en ámbitos de la comunicación, en particular las denuncias contra actos discriminatorios.

Es preciso tener en cuenta que al tratar sobre las diversidades sexo-genéricas, estas también se sitúan en medio de las relaciones antagónicas, el texto cita "La construcción del Poder Popular es el espacio de encuentro entre las luchas anticoloniales, 
anticapitalistas por las diversidades sexo-genéricas, por los derechos de las mujeres, derechos de los pueblos diversos" (Plan de Gobierno Alianza País, 2016:26).

Ahora bien, respecto a la posición del sujeto hablante, consideramos de vital importancia anotar que el Plan se relaciona directamente con Rafael Correa. El texto, además de tener impresa la firma del político, también guarda consonancia con los signos más sobresalientes del discurso del expresidente; la construcción de antagonismos, la interdiscursividad y la constitución de un pueblo identificado como un nosotros víctimas del pasado.

En lo que respecta a los temas de género, estos toman forma en la retórica de la experiencia, las acciones pasadas y la búsqueda de antagonismos. Exaltar la "década ganada" fundamentalmente se asocia a la continuidad del partido en el poder y además dota de cierta confiabilidad a las propuestas del Plan. Así, por ejemplo, prestando atención a uno de los tópicos identificados, se pudo apreciar que la noción de familia aparece como una estructura social beneficiada del desarrollo productivo alcanzado durante los diez años de la Revolución Ciudadana. Se hace hincapié en que la desigualdad económica, política y social en general tienen su origen en un neoliberalismo que limita "la familia que queremos formar" (Plan de Gobierno Alianza País, 2016:32). Estos enunciados además de reforzar la construcción antagónica en el discurso y apelar a la experiencia, traen a consideración una vez más el tópico familia, el cual ha sido evidentemente una preocupación capital en los discursos políticos analizados. El discurso apela constantemente a la familia desde el amor, el trabajo y en el orden tradicional y moral; padres y madres como la estructura que fomenta los valores, la 'célula básica de la sociedad'.

El discurso muestra los siguientes enunciados:

"Aprovechar la nueva plataforma, construida por todos los ecuatorianos con el esfuerzo de nuestro trabajo, puesta al servicio de ustedes, padres y madres de familia" (Plan de Gobierno Alianza País, 2016:33).

"La mitad de ecuatorianos y ecuatorianas que acceden al sistema de educación superior provienen de familias en las que ni el padre ni la madre accedieron a la Universidad" (Plan de Gobierno Alianza País, 2016:60).

Por otro lado, en el discurso también observamos que el tópico diversidad está presente a lo largo del texto. La diversidad que atiende el Plan es aquella que en el neoliberalismo quedó fuera, lo excluido de la visión dominante de las élites, de lo que debía ser "lo ecuatoriano", "un país de blancos-mestizos que históricamente han posicionado su visión del mundo en espacios publicitarios, medios de comunicación, textos escolares, etc." (Plan de Gobierno Alianza País, 2016:65). 
En lo relativo a la inserción del tópico $L G B T I$, el cual aparece por primera vez en un texto del corpus total de análisis, merece destacar que el Plan promueve la erradicación de la violencia hacia esta población:

Promoveremos la erradicación de toda forma de violencia hacia mujeres, niños y niñas, e impulsaremos políticas antidiscriminatorias hacia las personas Gays, Lesbianas, Bisexuales, Transgénero, Transexuales, Travestis e intersex" (Plan de Gobierno Alianza País, 2016:55).

Fortaleceremos el sistema de uniones libres del mismo sexo, pues es una forma de proteger a los cónyuges (Plan de Gobierno Alianza País, 2016:83).

Los temas que tienen que ver con la erradicación de la violencia de género, la exclusión y la discriminación por orientación sexual también se ajustan de alguna manera a la retórica populista; somos un pueblo, somos iguales, "hemos demostrado nuestro respeto a la diversidad y a todas las personas que antes eran discriminadas por su orientación sexual. No se puede hablar de respeto al pueblo, si no se reconocen los derechos" (Plan de Gobierno Alianza País, 2016:5).

\section{Conclusiones}

En el análisis realizado a los Planes de Gobierno de cuatro partidos políticos, verificamos que la agenda de temas relacionados al género toma forma en las retoricas de la división sexual del trabajo, la maternidad, la familia nuclear, el empleo, las prioridades, el discurso biológico y la institucionalidad como fuentes de veracidad.

Constatamos discursos que apelan a la masculinidad como condición de producción y utilización del discurso distinto a la mujer sitiada al espacio de lo privado y la maternidad. La temática del género y la sexualidad, es pensaba, ignorada e incluso prohibida por el sello de la institución de la religión cristiana, la cual actúa como fuente de legitimación y veracidad en estos discursos, asunto evidenciado en nuestras unidades de contexto. La búsqueda de la verdad y el rechazo por ejemplo a los intereses y demandas de los grupos LGBTI toman justificación en los valores y principios cristianos, desde donde se piensa a la familia y más ampliamente al país. De hecho, la familia como el tópico usado por excelencia en los Planes de Gobierno, es atravesada primordialmente por los valores religiosos, dejando de lado a otras identidades y expresiones sociales no articuladas con los parámetros de la heterormatividad y la familia nuclear-patriarcal que sirve de referente en estos discursos. Por otra parte, resulta interesante exponer que el tópico LGBTI, tienen un trato indiferente y silencioso en los discursos.

Finalmente, para profundizar en las dinámicas de construcción de los discursos políticos y electorales, se concluye que los Planes de Gobierno de ser un espacio de actividad política, de la privacidad inserta en lo público, en lugar de defender la 
diversidad reproduce y naturaliza el patriarcado. En estos documentos, se reproducen roles de género tradicionales del paradigma liberal. Existe una construcción o perfil de género particular; mayormente ignorado con una leve apertura en el discurso de corte más populista. El género, que aparece envuelto en la dicotomización del espacio social, enmarcado bajo la institución de la región católica, la tradición y la lógica de las prioridades, en suma, aspectos que merecen seguir siendo repensados en su complejidad mediante el análisis de los discursos y lograr una mayor comprensión e interpretación del lenguaje en las sociedades contemporáneas modernas.

\section{Bibliografía}

BOURDIEU, Pierre. (2000). La dominación masculina. Barcelona: Editorial Anagrama, S.A

CAMACHO, Margarita. (2016). Cuerpos deseantes y el armario político heterohomosexual. Quito: Abya-Yala

CHARADEAU, Patrick y Dominique MAINGUENEAU. (2005). Diccionario de análisis del discurso. Buenos Aires: Amorrortu editors

CRESPO, Ismael, Antonio GARRIDO y Mario RIORDA. (2008). La conquista del poder. Elecciones y campañas presidenciales en América Latina. Buenos Aires: La Crujía

EL COMERCIO (2016, diciembre 29). Derechos de las minorías se respetarán según mencionan los candidatos a la presidencia. Recuperado de http://www. elcomercio.com/actualidad/derechos-minorias-respeto-candidatos-elecciones. html

EL UNIVERSO. (2016, noviembre 17). Guillermo Lasso habla de devolver armas a los campesinos. Recuperado de https://www.eluniverso.com/noticias/2016/11/17/ nota/5907469/lasso-habla-devolver-armas-campesinos

FAIRCLOUGH, Norman. (1995). Critical discourse analysis. Harlow: Longman Group UK Ltd.

FAIRCLOUGH, Norman. (2003). Analysing discourse: textual analysis for social research. New York: Routledge https://doi.org/10.4324/9780203697078

FAIRCLOUGH, Norman. (2008). "El análisis crítico del discurso y la mercantilización del discurso público: las universidades”, Discurso y Sociedad Rev. 2 (1): 170-185

FAIRCLOUGH, Norman. y Wodak, Ruth. (2008). “Análisis crítico del discurso”. En T. VAN DIJK, (ed.), El discurso como interacción social. Barcelona: Gedisa, 367401.

FOUCAULT, Michael. (1988). La arqueología del saber. México: Siglo XXI Editores FOUCAULT, Michael. (1989). Historia de la sexualidad. La voluntad del Saber. México: Siglo XXI Editores 
FOUCAULT, Michael. (2002). El orden del discurso. Barcelona: Fabula Tusquets editores

FRASER, Nancy. (1997). "Pensando de nuevo la esfera pública: una contribución a la crítica de las democracias existentes", en BONILLA D., GARCÍA M., GAVIRIA M., y MOTTA C., (ed.), Justicia interrupta. Reflexiones críticas desde la posición postsocialista. Bogotá: Siglo del Hombre editores, Universidad de los Andes, 95-133.

FRASER, Nancy. (2003). "Nuevas reflexiones sobre el reconocimiento", New Left Review Rev. 4: 107-120

HALLIDAY, Michael. (1982). El lenguaje como semiótica social. México: Fondo de Cultura Económica

NEBOT, Jaime. (2018). Línea de tiempo [Página de Facebook]. Recuperado de https://es-la.facebook.com/jaimenebotsaadi/videos/10154428309418938/

KRIPPENDORF, Klaus. (1990). Metodología de análisis de contenido. Teoría y práctica. Barcelona, Piadós

LACLAU, E. (2006). "La deriva populista y la centroizquierda latinoamericana", Nueva Sociedad Rev. 205: 56-61

LA HORA. (2017, febrero 08). Abdalá Bucarám: Estoy convencido de que esta es mi elección. Recuperado de https://lahora.com.ec/noticia/1102028358/abdalc3a1bucarc3a1m-e28098estoy-convencido-de-que-esta-es-mi-eleccic3b3ne28099

LA POSTA. (2015, mayo 06) Castigamos a Lasso [Video] Recuperado de https:// www.youtube.com/watch?v=W7ED0feRnxc

LAZAR, Michelle. (2014). "Feminist Critical Discourse Analysis", en EHRLICH S., MEYERHOFF M., y HOLMES J., (ed.), The Handbook of Language, Gender, and Sexuality. Oxford: John Wiley and Sons, Inc., 180-199. https://doi. org/10.1002/9781118584248.ch9

PILLEUX, Mauricio. (1995). "El análisis del tópico en el discurso en una entrevista", Revista de Lingüística Teórica y Aplicada Rev. 33: 127-137.

PLAN DE GOBIERNO DEL MOVIMIENTO PAIS 2017-2021. (2016). Un programa para la sociedad, la educación, la producción y el trabajo digno. Recuperado de http://cne.gob.ec/images/d/2016/Elecciones_2017/Plan_de_Trabajo/ Alianza\%20Pais_lista\%2035.pdf

PLAN DE GOBIERNO DE PARTIDO POLÍTICO FUERZA ECUADOR 2017-2021. (2016). Plan de renacimiento económico y democrático del Ecuador. Recuperado de https://app05.cne.gob.ec/PLANES/6/721_asamProvG5.pdf

PLAN DE GOBIERNO DE LA ALIANZA CREO-SUMA 2017-2021. (2016). Por un Ecuador Justo, Próspero y Solidario. Recuperado de http://cne.gob.ec/ 
images/d/2016/Elecciones_2017/Plan_de_Trabajo/ALIANZA\%20CREO\%20 -\%20SUMA-1.pdf

PLAN DE GOBIERNO DEL PARTIDO SOCIAL CRISTIANO 2017-2021. (2016). Cambio Positivo. Recuperado de http://cne.gob.ec/images/d/2016/ Elecciones_2017/Plan_de_Trabajo/Partido\%20Social\%20Cristiano_lista\%206. pdf

PLAN V. (2017, marzo 20). La salomónica solución que Dalo Bucaram quiere dar al matrimonio gay. Recuperado de http://www.planv.com.ec/historias/sociedad/ la-salomonica-solucion-que-dalo-bucaram-quiere-dar-al-matrimonio-gay

ROSALDO, Michelle. (1979). "Mujer, cultura, sociedad: una visión teórica”, en HARRIS O., YOUNG K., (ed.), Antropología y feminismo. Barcelona: Anagram, 1-30.

RTU NOTICIAS. (2012, enero 25). Bucaram: Como puede hablar de hombría y valentía aquel que no puede reconocer su homosexualidad [Video]. Recuperado de https://www.youtube.com/watch?v=ousuHQNSFoA

MARILYN Strathern. (1979). “Género una perspectiva antropológica”, en HARRIS O., YOUNG K., (ed.), Antropología y feminismo. Barcelona: Anagrama, 133-152. UNSION TV. (2013, julio 02). Dalo Bucaram habla sobre el rescate de la familia [Video]. Recuperado de https://www.youtube.com/watch?v=RskBk1cYdJs

VAN DIJK, T. (2004). Discurso y Dominación. Bogotá: Universidad Nacional de Colombia

VAN DIJK, T. (2009). Discurso y Poder: contribuciones a los estudios críticos del discurso. Barcelona: Gedisa

WEST, Candace, Michelle LAZAR y Cheris KRAMARAE. (2008). "El género en el discurso", en Teun A. VAN DIJK, (ed.), El discurso como interacción social. Barcelona: Gedisa, 179-207.

WODAK, Ruth. (2003). "El enfoque histórico del discurso”, en WODAK R., y MEYER M, (ed.), Métodos de análisis crítico del discurso. Barcelona: Gedisa, 101-142.

YO VOTO CYNTHIA. (2016a). Línea de tiempo [Página de Facebook]. Recuperado de https://www.facebook.com/yovotocynthia/videos/167294960418351/

YO VOTO CYNTHIA. (2016b). Línea de tiempo [Página de Facebook]. Recuperado de https://www.facebook.com/yovotocynthia/videos/vb.158101421337705/195 $327710948409 /$ ?type $=2 \&$ theater 
